\title{
Kanserli bireylerin olumsuz duygudurumu düzenleme beklentileri
}

\section{The negative mood regulation expectations of cancer individuals}

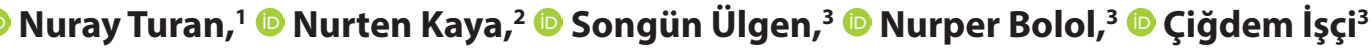 \\ İstanbul Üniversitesi-Cerrahpaşa Florence Nightingale Hemşirelik Fakültesi, İstanbul, Turkey \\ İstanbul Üniversitesi-Cerrahpaşa Sağlık Bilimleri Fakültesi, İstanbul, Turkey \\ İstanbul Üniversitesi-Cerrahpaşa Cerrahpaşa Tıp Fakültesi Hastanesi, Kulak Burun Boğaz Kliniği, İstanbul, Turkey
}

\begin{abstract}
Özet
Amaç: Bu araştırma, kanserli bireylerin olumsuz duygu durumu düzenleme beklentilerini saptamak amacı ile yapıldı.

Gereç ve Yöntem: Vaka-kontrol türde gerçekleştirilen araştırmanın evreni, İstanbul'da bir üniversite hastanesinin Kulak Burun Boğaz (KBB) Servisi'nde yatan hasta bireyler örneklemini ise, bu evren arasından gelişigüzel örnekleme yöntemi ile seçilen 47 kanser, 56 kanser olmayan birey oluşturdu. Veriler; Hasta Tanıtım Formu ve Olumsuz Duygudurumu Düzenleme Beklentileri Ölçeği (ODDBÖ) aracılığı ile toplandı. Elde edilen veriler; bilgisayarda uygun istatistiksel yöntemler kullanılarak analiz edildi.

Bulgular: Araştırma kapsamındaki kanserli bireylerin \%80.9'u erkek, yaş yılı ortalaması 59.49 (SS=11.73) yıl, beden kitle indeksi (BKi) ortalaması $25.23 \mathrm{~kg} / \mathrm{m}^{2}$ (SS=4.83); kanser olmayan bireylerin ise \%50'si erkek, yaş yılı ortalaması 35.07 (SS=13.88) yıl, BKi ortalaması $24.62 \mathrm{~kg} / \mathrm{m}^{2}$ (SS=4.55) olarak saptandı. Kanserli bireylerin ODDBÖ toplam puan ortalaması 100.21 (SS=18.94); kanserli olmayan bireylerin ise 110.61 (SS=19.67) olduğu görüldü. Kanser ve kanser olmayan bireylerin ODDBÖ toplam ( $p=0.004)$ ve Olumsuz Duygudan Uzaklaşma ( $p=0.003)$ alt ölçeği puan ortalamaları arasında, kanser olmayan bireylerin lehine, istatistiksel anlamlılık taşıyan farkın bulunduğu belirlendi.
\end{abstract}

Sonuç: Kanserli bireylerin olumsuz duygudurumu düzenleme beklentileri kanser olmayanlara göre daha düşüktür. Bu sonuç doğrultusunda, kanserli bireyin olumlu beklentiler geliştirebilmesi için hemşirelik bakımı stratejilerinin geliştirilmesi ve sonuçlarının değerlendirilmesi gerektiği söylenebilir.

Anahtar Sözcükler: Duygudurum; hemşirelik bakımı; kanser; sağlıklı/hasta birey.

\begin{abstract}
Introduction: This research was conducted with the aim to detect cancer of their negative mood regulation expectations.

Methods: The universe of the study, which was conducted in the casecontrol type, was the sample of the patients who were hospitalized in the Otolaryngology Department of a university hospital in Istanbul. Data; Patient Information Form and Negative Affect Adjustment Scale were collected through the questionnaire. The data obtained; were analyzed using appropriate statistical methods.

Results: $80.9 \%$ of the cancer patients were male, the mean age was 59.49 (SD=11.73), and the mean body mass index (BMI) was $25.23 \mathrm{~kg} /$ $\mathrm{m}^{2}(\mathrm{SD}=4.83) ; 50 \%$ of non-cancer patients were male, mean age was 35.07 ( $S D=13.88)$ and mean BMI was $24.62 \mathrm{~kg} / \mathrm{m}^{2}(\mathrm{SD}=4.55)$. The total score of the patients with cancer was 100.21 (SD=18.94); non-cancer patients were found to be 110.61 (SD=19.67). It was determined that there was a statistically significant difference between the non-cancer subjects in terms of total $(p=0.004)$ and out of Negative Emotion $(p=0.003)$ subscales.

Discussion and Conclusion: It was seen that individuals with cancer are less likely to experience negative mood than those without cancer. In line with these results, it is recommended to consider the factors affecting mood in order to ensure the individuality of health professionals.
\end{abstract}

Keywords: Cancer; healthy/illness individual; mood; nursing care.

*Bu bildiri 2-6 Kasım 2013 tarihleri arasında Antalya'da düzenlenen 7. Ulusal KBB Hemşirelik Kongresi'nde sözel bildiri olarak sunulmuştur.

Corresponding (IIletişim): Nuray Turan, İstanbul Üniversitesi-Cerrahpaşa Florence Nightingale Hemşirelik Fakültesi, Şişli, İstanbul, Turkey E-mail (E-posta): nkaraman@istanbul.edu.tr; nuray_karaman@yahoo.com

Received (Geliş Tarihi): 29.10.2018 Accepted (Kabul Tarihi): 06.03.2019 
$\mathrm{T}$ ürk Dil Kurumu' Sözlüğü (TDK)'nde duygudurum (mood); sevinçli, dertli ya da coşkusal bir tepki göstermek için kişinin içsel hazırlığı; ruh durumu, kimi zaman kısa, kimi zaman uzun süren duygusal koşul ya da tutum olarak tanımlanmaktadır. ${ }^{[1]}$ Duygudurum (ruh hali, mood) genel ve nispeten uzun süreye yayılmış ve bireyin deneyimlediği ruhsal tonüsü belirtir. Örneğin; intihar etmeye kesin olarak karar vermiş olan bir melankolik birey, gülümseyerek sizi aldatabilir; aslında bireyin duygudurumu derin bir elem ve ümitsizlikle doludur, sadece acısına son vereceği için gülümsemektedir. İyi bir gözlem ile (bazen de uzun süreli), anlık affektif değişiklikler de dahil, genel ruhsal durum muayenesi sonucunda belirlenir. Mesela, sağlıklı/hasta birey değişik zaman kesitlerinde sıkıntılı, neşeli, öfkeli veya çökkün olabilir ama ayrıntılı gözlemden sonra "hasta bireyin duygudurumu, zaman zaman affektif (duygulanımsal) canlanmalar ve irritabilite sergilemekle beraber depresifti" olarak tanılanabilir. ${ }^{[2]}$

Olumlu ve olumsuz duygu içerikleri arasında: mutlu-mutsuz; öfkesiz-öfkeli; stressiz-stresli; sevinçli-hüzünlü; yeterli-yetersiz; tutarlı-tutarsız; sakin-sinirli; keyifli-keyifsiz; iyimser-kötümser; kaygısız-kaygılı; güçlü-güçsüz; umutlu-umutsuz; huzurlu-huzursuz; istekli-isteksiz; cana yakın-soğuk; rahat-gergin; neşeli-üzgün; kararlı-kararsız; heyecanlı-heyecansız; uyumlu-uyumsuz; sabırII-sabırsız; aktif-pasif; güvenli-güvensiz; canlı-durgun; kontrolü-kontrolsüz; sevecen-hırçın; dikkatli-dalgın; girişken-çekingen; duygulu-duygusuz; esprili-sıkıcı yer almaktadır. ${ }^{[3]}$

Duygusal süreçlerin, insanların düşüncelerini ve davranışlarını etkilediği uzun süredir bilinmektedir. Duygudurum dikkat, bellek, bilgi işleme gibi bilişsel yapıları etkilemektedir. Ayrıca, duygudurumun yardım etme, sosyal ilişkiler, dışadönüklük, performans, işten ayrılma, liderlik, çatışma çözümü gibi alanlarla da ilişkisi bulunmaktadır. ${ }^{[4]}$ Watson ve Tellegen ${ }^{[5]}$, duyguların sınıflanmasında pozitif ve negatif duygudurumun kullanılabileceğini öne sürmüştür. Çeşitli duygular, bu eksen içinde değerlendirilmiştir. Duygudurum genel olarak pozitif ve negatif ruh halini betimlerken, duygular kısa sürelidir ve genellikle sonradan duyguduruma dönüşür. ${ }^{[6]}$ Duygular, genellikle algılayan bireyler tarafından fark edilirken, duygudurum deneyimleyen birey tarafından pek fark edilmez. ${ }^{[4]}$

Mutlu veya olumlu duygudurumda olan insanların oranını dünya çapında belirleyen en geniş tarama 41 ülkede 60.000 kişiyle yapılmıştır. Araştırmanın sonucuna göre insanların \%64'ü olumsuz duygulara kıyasla olumlu duygular yaşadıklarını, öte yandan \%16'sı ise olumlu duygulara kıyasla olumsuz duygular yaşadıklarını ifade etmiştir. ${ }^{[7]}$ Bu araştırmanın sonucunu yorumlayan bilim insanlarına göre; insanların daha olumlu duyguduruma sahip olmasının nedenlerinden biri, sürekli olarak olumlu duygudurum yaşayanların çevrelerinde ödüllere daha duyarlı olmalarıdır. Bir diğer açıklamaya göre, bu bireyler çevreye veya ödüllere karşı daha yaklaşımcı bir sisteme sahiptir. ${ }^{[8]}$ Başka bir deyişle, bireyler ödüllerin olduğu durumlarda kaçınma yerine ödüllere ulaşmayı daha fazla tercih etmektedirler. ${ }^{[4]}$

Duygular, insan yaşamında zihinsel, bedensel ve davranışsal öğelerle birlikte kendini gösteren bir yapı ortaya koymakta- dır. Duygular, insan yaşamını zenginleştiren, renklendiren, yaşamla baş etmeyi sağlayan bir unsur olarak anıldıkları gibi duyguların kontrolü konusundaki yetersizlikler bu baş etme becerisinde yetersizliklerin nedeni olarak da görülmektedir. Bireylerin duygularına yönelik farkındalık sahibi olmasının, duyguları değerlendirirken yaşanılan bütün duyguların olumlu ya da olumsuz olarak tanımlamak yerine her birinin yaşantısal önemine dikkat etmesinin, yaşam becerilerini daha güçlü hale getireceği düşünülmektedir.

Duygudurum düzenlemesi konusunda yapılan çalışmalar, genellenmiş bir sorun çözme beklentisinin, duygusal benlik düzenlemesinde önemli bir boyut olduğunu ortaya koymuştur. Bu beklenti, bireyin repertuarındaki davranışların, çeşitli sorunların çözümünde etkili olacağına yönelik öznel inançtır. Olumsuz duygudurumu düzenleme beklentileri, bireylerin herhangi bir olumsuz duygudurumunu azaltma veya sonlandırma ile ilgili kendi becerilerine ilişkin inançlarını yansıtır. Olumsuz duygulardan kurtulabileceklerine ilişkin güçlü beklentisi olan bireyler, baş etme yöntemlerini daha etkili kullanabilmekte ve stresli durumlarda böyle bir beklentisi olmayan bireylere göre daha az fiziksel yakınmalar gelişmektedir. ${ }^{[8,9]}$ Kanser tanısı çok önemli bir stresördür ve böyle bir durumda bireyin hastalığa uyumu gerekmektedir. Kanserli bireylerde olumsuz duygulardan kurtulabileceklerine ilişkin beklentilerin oluşturulması, hastalığa uyumda bir strateji olarak düşünülebilir. Bunun için öncelikle kanserli bireylerin olumsuz duygudurumu düzenleme beklentileri saptanmalıdır.

\section{Gereç ve Yöntem}

\section{Araştırmanın amacı ve türü}

Bu araştırma, kanserli bireylerin olumsuz duygu durumu düzenleme beklentilerini saptamak amacı ile vaka-kontrol türde yapıldı.

\section{Araştırmanın evreni ve örneklem seçimi}

Araştırmanın evreni, İstanbul'da bir üniversite hastanesinin Kulak Burun Boğaz (KBB) Servisi'nde yatan hasta bireylerden meydana geldi. Bu evren arasından 47 kanser, 56 kanser olmayan birey gelişigüzel örnekleme yöntemi ile araştırma kapsamına alındı.

\section{Veri toplama araçları}

Veri toplama aracı olarak; Hasta Tanıtım Formu ve Olumsuz Duygudurumu Düzenleme Beklentileri Ölçeği (ODDBÖ) kullanıldı.

Hasta Tanıtım Formu: Konu ile ilgili literatür ${ }^{[2,4,6]}$ rehberliğinde hazırlanmış olup cinsiyet, yaş, medeni durum, çocuk sahibi olma durumu, boy ve kilo değişkenlerinden oluşmaktadır.

Olumsuz Duygudurumu Düzenleme Beklentileri Ölçeği (ODDBÖ): Özgün adı Negative Mood Regulation Expectancies Scale (NMR) olan ölçeği Catanzaro ve Mearns ${ }^{[9]}$ geliştirdi ve Türkçeye uyarlaması Bahadır ${ }^{[10]}$ tarafından yapıldı. Beşli likert tipi ölçüm sağlayan ve 30 maddeden oluşan ölçek; bireyin olumsuz duygudurumunu başarılı bir şekilde azaltabileceğine dair inancını değerlendirmek amacıyla geliştirildi. Ölçekten elde edilen 


\section{Tablo 1. Kanser ve kanser olmayan bireylerin bireysel özelliklerinin dağılımı}

\begin{tabular}{|c|c|c|c|c|}
\hline Bireysel özellikler & $\begin{array}{c}\text { Kanser }(n=47) \\
n(\%)\end{array}$ & $\begin{array}{c}\text { Kanser olmayan }(n=56) \\
n(\%)\end{array}$ & $\begin{array}{c}\text { Toplam }(n=103) \\
n(\%)\end{array}$ & $\begin{array}{c}\mathrm{X}^{2} / \mathrm{Z}^{\mathrm{MW}} \\
\mathbf{p}\end{array}$ \\
\hline \multicolumn{5}{|l|}{ Cinsiyet } \\
\hline Erkek & $38(80.9)$ & $28(50.0)$ & $66(64.1)$ & $p=0.001$ \\
\hline \multicolumn{5}{|l|}{ Yaş sınıfları } \\
\hline 54 ve üstü & $33(70.2)$ & $7(12.5)$ & $40(38.8)$ & \\
\hline Yaş (Min-Maks.) & $(30-75)$ & $(18-67)$ & $(18-75)$ & $Z^{\mathrm{MW}}=-6.843$ \\
\hline Ort. \pm SS & $59.49 \pm 11.73$ & $35.07 \pm 13.88$ & $46.21 \pm 17.76$ & $p=0.000$ \\
\hline \multicolumn{5}{|l|}{ Medeni durum } \\
\hline Evli & $39(83.0)$ & $23(41.1)$ & $62(60.2)$ & $X^{2}=18.730$ \\
\hline Yok & $5(10.6)$ & $34(60.7)$ & 39 (37.9) & $p=0.000$ \\
\hline \multicolumn{5}{|l|}{ BKİ sınıfları } \\
\hline 18.5 altı & $3(6.4)$ & $1(1.8)$ & $4(3.9)$ & \\
\hline $18.5-24.9$ & $24(51.1)$ & $30(53.6)$ & $54(52.4)$ & $X^{2}=2.046$ \\
\hline $25-29.9$ & $14(29.8)$ & $20(35.7)$ & $34(33.0)$ & $p=0.563$ \\
\hline 30 ve üstü & $6(12.8)$ & $5(8.9)$ & $11(10.7)$ & \\
\hline BKI (Min-Maks.) & (17.18-36.89) & (16.94-41.62) & $(16.94-41.62)$ & $Z^{\mathrm{MW}}=-0.672$ \\
\hline Ort. \pm SS & $25.23 \pm 4.83$ & $24.62 \pm 4.55$ & $24.90 \pm 4.67$ & $p=0.502$ \\
\hline
\end{tabular}

Ort.: Ortalama; SS: Standart sapma; Min.: Minimum; Maks. Maksimum; BKI: Benden kitle indeksi.

Tablo 2. Hastaların Olumsuz Duygudurumu Düzenleme Beklentileri Ölçeğinden aldıkları puanların dağılımı (n=107)

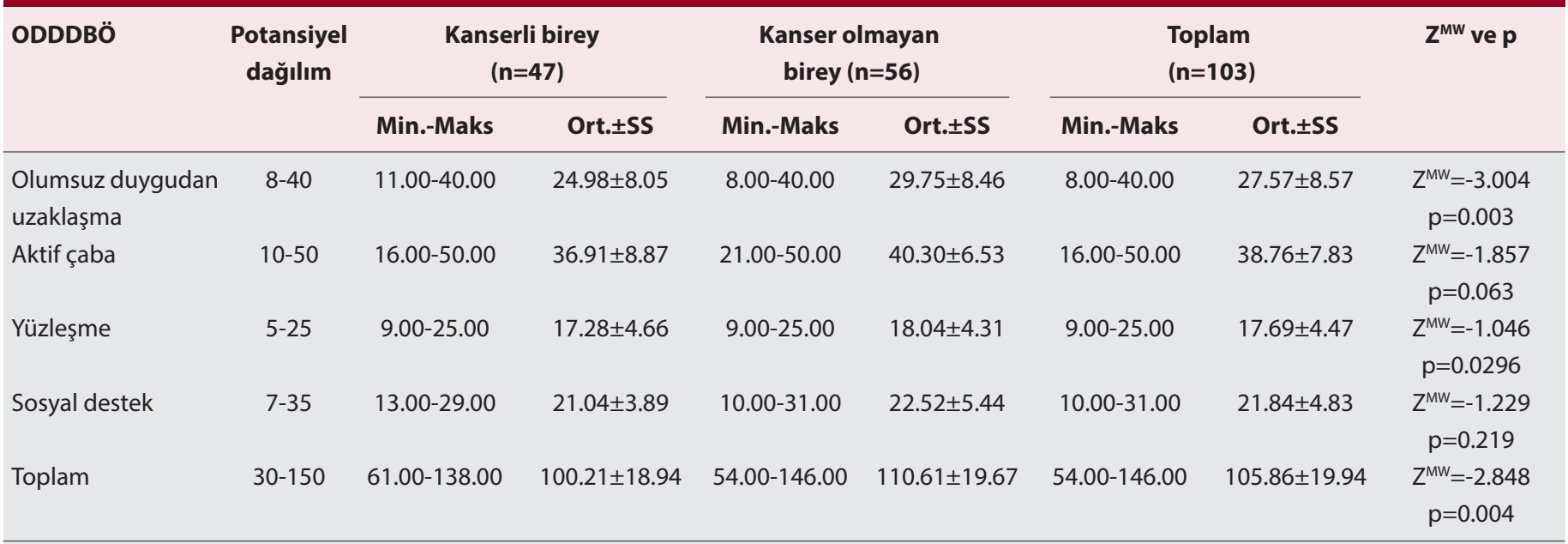

ODDDBÖ: Olumsuz Duygudurumu Düzenleme Beklentileri Ölçeği; Ort.: Ortalama; SS: Standart sapma; Min.: Minimum; Maks. Maksimum.

yüksek puan, bireyin olumsuz duygudurumunu azaltabilme başarısına olan güçlü inancını göstermektedir. Ölçek maddelerine verilen puanlar toplanarak, ölçeğin genel puanı belirlenmektedir ve olası en düşük puan 30, olası en yüksek puan ise 150 'dir. Bahadır'ın ${ }^{[10]}$ çalışmasında yaptığı faktör analizine göre; ODDB ölçeği Olumsuz Duygudan Uzaklaşma (ODU), Ak- tif Çaba (AÇ), Yüzleşme (Y) ve Sosyal Destek (SD) olmak üzere dört alt boyuttan oluşmaktadır.

\section{Araştırmanın etik yönü}

Araştırmaya başlamadan önce kurumdan yazılı, hastalardan sözlü bilgilendirilmiş olur alındı. Örneklemi oluşturan has- 
ta bireylere; çalışmanın amaç ve yararları, çalışmadaki rolleri açıklandı, veri toplama formları üzerine isim yazmamaları ve istedikleri aşamada araştırmadan ayrılabilecekleri söylendi, araştırmaya katılmaya isteklilik, gönüllülük ilkesine özen gösterilerek sözlü olurları alındı.

\section{Verilerin analizi ve değerlendirilmesi}

Toplanan veriler IBM SPSS 21.00 programında veri tabanına girildi ve tüm istatistiksel analizler aynı programda gerçekleştirildi. Sürekli değişkenler aritmetik ortalama, standart sapma, minimum ve maksimum değerleri olarak, kategorik değişkenler ise frekans ve yüzde olarak ifade edildi. Elde edilen verilerin normallik analizi için Bir Grupta Kolmogorov-Smirnov Uyum İyiliği Testi uygulandı. Dağılımların normal olmadığı saptanarak ordinal değişkenler arasındaki ilişkinin belirlenmesinde Spearman's rho korelasyon Tekniği, iki grubun ortalamalarının karşılaştırılmasında Mann-Whitney U-testi kullanıldı. ${ }^{[11,12]}$

\section{Bulgular}

Araştırma kapsamındaki kanserli bireylerin \%80.9'u erkek, yaş yılı ortalaması 59.49 (SS=11.73), \%83'ü evli, \%89.4'ü çocuk sahibi, \%40.4'ü çalışıyor, beden kitle indeksi (BKi) ortalaması $25.23 \mathrm{~kg} / \mathrm{m}^{2}$ (SS=4.83); kanser olmayan bireylerin \%50'si erkek, yaş yılı ortalaması 35.07 (SS=13.88), \%41.1'i evli, \%39.3'ü çocuk sahibi, \%53.6'sı çalışıyor, BKì ortalaması $24.62 \mathrm{~kg} / \mathrm{m}^{2}$ (SS=4.55) olarak saptandı. Kanser ve kanser olmayan bireylerin cinsiyet $\left(x^{2}=10.566 ; p=0.001\right)$, yaş $\left(Z^{\mathrm{MW}}=-6.843 ; p=0.000\right)$, medeni durum ( $\left.x^{2}=18.730 ; p=0.000\right)$, çocuk sahibi olma $\left(x^{2}=27.236\right.$; $p=0.000$ ) değişkenlerine göre eşlenik olmadığı, öte yandan incelenen çalışma durumu ve BKi değişkenleri yönünden her iki grup arasında anlamlı farklılı̆ın bulunmadığı $(p>0.05)$ belirlendi. Kanserli bireylerin ODDBÖ ve alt boyut puan ortalamalarının Olumsuz Duygudan Uzaklaşmada (potansiyel dağılım: 8-40) 24.98 (SS=8.05), Aktif Çabada (potansiyel dağılım:10-50) 36.91 (SS=8.87), Yüzleşmede (potansiyel dağılım: 5-25) 17.28 (SS=4.66), Sosyal Destekte (potansiyel dağılım: 7-35) 21.04 (SS=3.89), toplamda (potansiyel dağılım: 30-150) 100.21 ( $S S=18.94)$; kanserli olmayan bireylerin ise Olumsuz Duygudan Uzaklaşmada 29.75 (SS=8.46), Aktif Çabada 40.30 (SS=6.53), Yüzleşmede 18.04 ( $\mathrm{SS}=4.31$ ), Sosyal Destekte 22.52 ( $\mathrm{SS}=5.44$ ), toplamda 110.61 ( $S S=19.67)$ olduğu görüldü. Kanser ve kanser olmayan bireylerin ODDBÖ toplam $\left(Z^{\mathrm{MW}}=-2.848 ; \mathrm{p}=0.004\right)$ ve Olumsuz Duygudan Uzaklaşma ( $Z^{\mathrm{MW}=-3.004 ;} \mathrm{p}=0.003$ ) alt ölçeği puan ortalamaları arasında, kanser olmayan bireylerin lehine, istatistiksel anlamlılık taşıyan farkın bulunduğu belirlendi.

\section{Tartışma}

Olumsuz duygudurumu düzenleme beklentisi, insanların olumsuz duygudurumu değiştirebilmesine özgü inançlarını ifade etmektedir. ${ }^{[13]}$ Olumsuz duygudurumu düzenleme durumu, özellikle kanser hastalarında olumsuz duygudurumunu azaltma veya sonlandırma ile ilgili kendi becerilerine ilişkin inançlarını yansıtır.
Kanserli bireylerin Olumsuz Duygudurumu Düzenleme Beklentileri, kanserli olmayan bireylere göre daha düşük olmakla birlikte grupların birbirlerine yakın değerlerde ve ölçek puanlarının orta düzeyde olduğu görüldü. Hastalık, tıbbi açıdan fizyopatolojik-organik süreçleri içeren, hasta için ise biyofizyolojik, psikolojik, sosyo-kültürel ve politiko-ekonomik boyutları olan bir olgu, bir yaşam, kimlik ve varoluş krizidir ${ }^{[13]}$ Kanser fiziksel bir hastalık olduğu gibi, ruhsal ve sosyal bileşenleri de olan bir sorundur. Kanser hastaları tanı, tedavi ve terminal dönemlerde çeşitli ve değişik duygusal, davranışsal yanıtlar geliştirirler ve yanıtlar bireyden bireye farklılık gösterir. ${ }^{[14]}$ Literatür de, kontrol edilemeyen yaşam olayları sonucunda olumsuz duygudurumu beklentisinin olabileceğini göstermiştir. ${ }^{[14,15,16]}$ Açıkmeşe'nin ${ }^{[13]}$ çalışmasında, ODDBÖ sonuçlarına göre, hasta grubunun puan ortalaması 112.80; kontrol grubunun ise 115.73 olarak bulunmuştur. Araştırma bulgusuna göre, her iki grubun, olumsuz duygudurumu düzenleme beklentisinin birbirine yakın düzeylerde olduğu ifade edilebilir.

Kanser olmayan bireylerin Olumsuz Duygudurumu Düzenleme Beklentileri ve Olumsuz Duygudan Uzaklaşma alt ölçeğinden kanser olanlara göre en yüksek puanları aldıkları belirlendi. Olumsuz duygudurum düzenleme beklentileri, duygudurum üzerinde kendini kontrol etme etkilerine sahip olma eğilimini ve kendini daha iyi hissetme beklentisini ifade eder. Bireyin daha iyi hissedeceği inancı, kullandığı baş etme stratejilerinden bağımsız olarak duygudurumunu düzenlemek için yeterli olabilir. ${ }^{[17]}$ Kansere karşı hissedilen çaresizlik duygusu, tedavinin yan etkileri ve kanserin yol açtığı fiziksel belirtiler, kanserli bireylere bedenlerini kontrol edemedikleri duygusu yaşatmaktadır. ${ }^{[18]}$ Kanser olan bireylerde olumsuz duygudurum düzenleme beklentilerinin etkisi, depresyon, anksiyete, öfke ve diğer duygusal sıkıntı belirtileri ile ilişkili olduğu saptanmıştır. ${ }^{[19,20,21]}$ Araştırmanın bu bulgusu, literatür ve çalışma bulguları ile uyumludur.

\section{Araştırmanın sınırlıı̆̆ı}

$\mathrm{Bu}$ araştırmanın en önemli sınırlıı̆̆ kanser ve kanser olmayan bireyleri oluşturan grupların cinsiyet ve yaş açısından eş olmamasıdır. Bu sınırlılığa rağmen elde edilen veriler yorumlandığında, kanserli bireylerin özellikle olumsuz duygudan uzaklaşma olmak üzere genel olarak olumsuz duygudurumu düzenleme beklentileri ile iyi baş edemedikleri ve bu gereksinimlerinin karşılanması gerektiği ifade edilebilir.

\section{Sonuç}

Kanser ve kanser olmayan bireylerin Olumsuz Duygudurumu Düzenleme Beklentileri'ini orta düzeyde olduğu görüldü. Kanser olmayan bireylerin ODDBÖ toplam ve Olumsuz Duygudan Uzaklaşma alt ölçeğinin kanser olanlara göre yüksek bulundu.

\section{Bu sonuçlar doğrultusunda;}

- Kanserli bireyin bireyselliğini sağlayabilmek için duygudurumu etkileyen faktörlerin göz önünde bulundurulması,

- Hizmet içi eğitim programları ile sağlıklı/hasta bireye ve yakınlara psikososyal yaklaşım konularında tekrarlı eğitimler yapılması önerilebilir. 
Çıkar çatışması: Bildirilmemiştir.

\section{Kaynaklar}

1. Türk Dil Kurumu 2018, http://www.tdk.gov.tr/index.php?option=com_bts\&view=bts\&kategori1=veritbn\&kelimesec $=329572$. Erişim Tarihi: 01.10.2018.

2. Doksat K. Mizaç, karakter, kimlik, kişilik, duygudurum ve duygulanım nedir? Birinci Basamak l̇çin Psikiyatri 2003; 2(2): 9-15.

3. Er N. Duygu durum sıfat çiftleri (DDSÇ) Listesi. İstanbul Çalışmaları Dergisi 2006; 26: 21-43.

4. Coşkun H, Gültepe B. Duygudurum ve bazı davranışlarımız: yeni bulgular ışığında bir değerlendirme. AïBÜ Sosyal Bilimler Enstitüsü Dergisi 2013; 13(2): 81-100.

5. Watson D, Tellegen A. Toward a consensual structure of mood. Psychological Bulletin 1985; 98(2): 219-35.

6. Barsade $\mathrm{S}$, Gibson, DE. Why does affect matter in organizations? Academy of Management Executive 2007; 36-59.

7. World Value Survey Group http://www.worldvaluessurvey.org/ wvs.jsp. Erişim Tarihi: 01.10.2018.

8. Lyubomirsky S, King L, Dianer E. The benefits of frequent positive affect: Does happiness lead to success? Psychological Bulletin 2005; $131(6):$ 803-55.

9. Catanzaro SJ, Mearns J. Measuring generalized expectancies for negative mood regulation: Initial scale development and implications. Journal of Personality Assessment, 1990; 54: 546-63.

10. Bahadır Ş. Romantik ilişkilerde bağlanma stilleri çatışma çözme stratejileri ve olumsuz duygudurumunu düzenleme arasındaki ilişki. Ankara Üniversitesi Sosyal Bilimler Enstitüsü, Doktora Tezi, Ankara; 2006.

11. Akgül A. Tıbbi araştırmalarda istatistiksel analiz teknikleri "SPSS uygulamaları". 3. Baskı, Emek Ofset Ltd Şti: Ankara; 2005.

12. Özdamar K. SPSS ile biyoistatistik, 5. baskı, Kaan Kitabevi: İstanbul; 2003.

13. Açıkmeşe IN. Kanser hastalarında iç-dış kontrol odağının depresyon üzerine etkisinin araştırılması. İstanbul Üniversitesi Sağlık Bilimleri Enstitüsü, Yüksek Lisans Tezi, İstanbul; 2007.

14. Tünel M, Vural A, Evlice YE, Tamam L. Meme kanserli hastalarda psikiyatrik sorunlar. Arşiv Kaynak Tarama Dergisi 2012; 189-219.

15. Er N, Hoşrik E, Ergün H, Şerif M. Duygu durum değişimlemelerinin otobiyografik bellek üzerindeki etkileri. Türk Psikoloji Dergisi 2008; 23(62): 1-13.

16. Diehl M, Hay EL. Personality-related risk and resilience factors in coping with daily stress among adult cancer patients. Research in Human Development 2013; 10(1): 47-69.

17. Kirsch I, Mearns J, Catanzaro SJ. Mood-regulation expectancies as determinants of dysphoria in college students. Journal of Counseling Psychology 1990; 37: 306-312.

18. Fawzy FI, Fawzy NW, Pasnau RO, Arndt LA. Critical review of psychosocial interventions in cancer care. Arch Gen Psychiatry 1995; 52(2): 100-113.

19. Sucala ML, Tatar AS. Optimism, pessimism and negative mood regulation expectancies in cancer patients. Journal of Cognitive and Behavioral Psychotherapies 2010; 10(1):13-24.

20. Surmann AT. Negative mood regulation expectancies, coping and depressive symptoms among American nurses. Journal of Social Psychology 1999; 139: 540-543.

21. Catanzaro JS. Negative mood regulation expectancies moderate the association between happiness emotion goals and depressive symptoms. Personality and Individual Differences 2016; 100: 23-27. 